\title{
Studies on the Adsorption of Indigo Dye From Aqueous Media Onto Carbonised Sugarcane Bagasse \\ ${ }^{*}$ O. Sanda, K. I. Amoo and E. A. Taiwo \\ Department of Chemical Engineering, Obafemi Awolowo University, lle-Ife, Nigeria \\ [ ${ }^{\star}$ Corresponding Author: E-mail: osanda@oauife.edu.ng, eataiwo@yahoo.com]
}

\begin{abstract}
The ability of Carbonised Sugarcane Bagasse (CSB) to remove indigo dye from aqueous solutions is being studied. Adsorption studies were carried out at different contact time and adsorbent dosage, and the sorption data were modelled using Langmuir, Freundlich and Temkin adsorption isotherms. The results showed that equilibrium was reached within $60 \mathrm{~min}$. Equilibrium data of the adsorption process fitted the Langmuir model $\left(R^{2}=0.9848\right)$. Three simplified kinetic models including a pseudo-first-order equation, pseudo-second-order equation and intraparticle diffusion equation were selected to follow the adsorption process. Kinetic parameters, rate constants, equilibrium sorption capacities and related correlation coefficients, for each kinetic model were calculated and discussed. It was shown that the adsorption of indigo dye could be described by the pseudo-second order equation $\left(R^{2}=0.9960\right)$, indigo dye is transported via intraparticle diffusion into the particles and is finally retained in micropores, suggesting that the adsorption is presumably a physisorption process.
\end{abstract}

\section{INTRODUCTION}

The textile industry is a water intensive industry with water being used in every stage of wet operations such as dyeing, bleaching, finishing and printing of fabrics (Mohan et al., 2005). Every textile plant requires large volumes of water and produces high volumes of effluent wastewater which contains a number of contaminants such as dyes, buffers, bleaches and scouring agents, water softeners, surfactants, enzymes, caustic compounds and acids (Venceslau et al., 1994). Discharging large amount of dyes accompanied by organics, bleaches and salts into water bodies can affect the physical and chemical properties of the water (Zaheer et al., 2014). In addition to imparting unwanted colours to water bodies, some dyes may degrade to produce toxic products (Hameed et al., 2008; Zaheer et al., 2014; Rizwana and Uma, 2015).

Different physical and chemical treatments such as flocculation and coagulation (Rodrigues et al., 2013; Zahrim and Hilal, 2013), oxidation (Zaharia et al., 2009; Sohrabi et al., 2014), membrane separation (Zheng et al., 2013) and adsorption (Qiu et al., 2009; Sayal et al., 2012; Bharathi and Ramesh, 2013; Mittal et al., 2013) are used to treat dye containing waste water. Adsorption has been found to be superior to other methods for waste water recycling in terms of initial cost, simplicity of design, use of operation and insensitivity to toxic substances (Sayal et al., 2012). The removal of coloured and colourless organic pollutants from industrial waste water is considered as an important application of adsorption processes (Yavuz and Aydin, 2006).

Activated carbon has been the most widely used adsorbent because of its high capacity for the adsorption of organic species and dye. However, due to the difficulty and expense involved in regeneration, agricultural wastes such as rice husk (de Luna et al., 2013), maize cob (Saroj et al., 2015), wheat straw (Su et al., 2013), breadfruit peels (Chieng et al., 2015) and banana peels (Mohammed and Chong, 2014) are considered as alternative low cost adsorbents. One of the low cost materials of agricultural origin that can be used is sugarcane bagasse. Sugarcane bagasse is the fibrous matter that remains after sugarcane stalks are crushed. Bagasse is an extremely inhomogeneous material comprising around $40 \%$ of pith fibre, which is derived from the core of the plant and is mainly parenchyma material, and "stem" fibre, 


\section{Sanda et al: Studies on the Adsorption of Indigo Dye From Aqueous Media Onto Carbonised......}

which comprises the balance and is largely derived from sclerenchyma material (Zaheer et al., 2014).

Keeping in view the significance of dyes and the environmental problems associated with their disposal, this study is designed to explore the adsorption potential of carbonized sugarcane bagasse (CSB) for the removal of indigo dye (a dye stuff commonly used by local "tie and dye" outlets in Southwestern Nigeria) from aqueous solution.

\section{MATERIALS AND METHODS}

\section{Sample Preparation}

Indigo dye was obtained from a local tie and dye outlet in lle-lfe, Nigeria while sugarcane bagasse was collected from Sabo market in Ile-lfe. The collected sugar cane bagasse was washed several times to remove dust and sugar residue, rinsed several times with distilled water to remove the sugar residue and dried overnight in an oven at $105^{\circ} \mathrm{C}$, followed by grinding and sieving to obtain particles smaller than $1 \mathrm{~mm}$. Carbonization was carried out for 2 hour in limited air supply at $500{ }^{\circ} \mathrm{C}$ in a muffle furnace. The carbonized sample was cooled and soaked for 24 hour in orthophosphoric acid $\left(\mathrm{H}_{3} \mathrm{PO}_{4}\right)(25 \mathrm{~g}$ of carbonized sample in $500 \mathrm{~mL}$ of $1.0 \mathrm{M}$ solution of $\mathrm{H}_{3} \mathrm{PO}_{4}$ ), dried at $105^{\circ} \mathrm{C}$ and finally activated in a furnace at $500{ }^{\circ} \mathrm{C}$ for 3 hours. The activated sample (CSB) was allowed to cool to room temperature, washed with distilled water, dried in an oven at $105^{\circ} \mathrm{C}$ to constant weight and finally kept in an air tight container for use. A 500 ppm stock solution of indigo dye solution was prepared and solutions of different concentrations ranging from 2 - 50 ppm were made by further dilutions.

\section{Experimental Procedure Adsorption Studies}

The batch adsorption studies for indigo dye on CSB was carried in $250 \mathrm{~mL}$ conical flasks by mixing pre-weighed amount of the powdered adsorbent in $50 \mathrm{~mL}$ of the aqueous dye solution of particular concentration. The conical flasks were kept at $30{ }^{\circ} \mathrm{C}$ in a thermostat controlled shaker bath (Brunswick) and were shaken for a predetermined time interval at $120 \mathrm{rpm}$. The adsorbent was separated by centrifugation and the concentration of dye left in the supernatants was determined spectrophotometrically at 580 $\mathrm{nm}$. The amount of dye adsorbed per mass of the adsorbent was determined using:

$$
q_{e}=\frac{\left(C_{i}-C_{e}\right) V}{w}
$$

where $q_{e}(\mathrm{mg} / \mathrm{g})$ is the equilibrium adsorption capacity, $C_{i}$ and $C_{e}(\mathrm{mg} / \mathrm{L})$ are the initial and equilibrium liquid phase concentrations of the dye, respectively, $V(I)$ is the initial volume of dye solution, and $\mathrm{w}(\mathrm{g})$ is the weight of the adsorbent. Also, the amount of indigo dye adsorbed at time $t$, $\mathrm{q}_{\mathrm{t}}(\mathrm{mg} / \mathrm{g})$ was calculated by:

$q_{t}=\frac{\left(C_{i}-C_{t}\right) V}{w}$

where $\mathrm{C}_{t}$ is the dye concentration at any time, $\mathrm{t}$.

\section{Adsorption kinetics and equilibrium determination}

For the determination of adsorption kinetics and isotherms, $1000 \mathrm{~mL}$ of $50 \mathrm{mg} / \mathrm{L}$ solution of indigo dye was mixed with an adsorbent dose varying from 5 to $25 \mathrm{~g}$ at 145rpm using a Gallenhamp Handilab SS 425 stirrer for contact times varying from 10 to $60 \mathrm{~min}$. At the end of each run, the concentration of the dye left in the beaker was determined spectrophotometrically at $580 \mathrm{~nm}$ using a Cecil 7400 UV - visible spectrophotometer. All experiments were done in duplicate for isotherm establishment and kinetic studies.

\section{RESULTS AND DISCUSSION Adsorption Kinetics Modelling}

The rate of sorption is important for designing batch adsorption experiments. Therefore, the effect of contact time on the adsorption of indigo dye was investigated.

The results as presented in Figure. 1 clearly show that the adsorption of indigo dye onto CSB attained equilibrium in less than 20 min. The fast initial uptake in the first 10 min can be attributed to the accumulation of the dye on the CSB 
surface. As reported by Ragheb (2013), the mechanism of solute transfer to the solid includes diffusion through the layer or fluid film around the adsorbent particle and diffusion through the pores to the internal adsorption sites. Initially the concentration gradient between the layer or film and the solid surface is large, and hence the transfer of solute onto the solid surface is faster. As time increases (beyond $10 \mathrm{~min}$ in this case), intraparticle diffusion becomes dominant and the solute takes more time to transfer from the solid surface to internal adsorption sites through the pores.

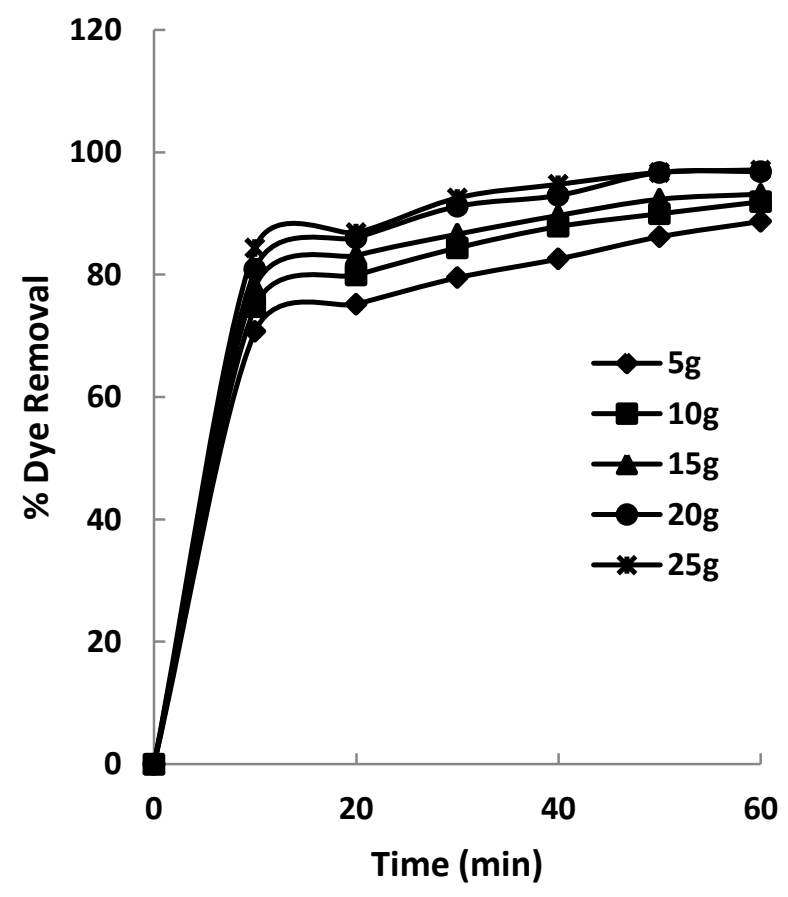

Figure 1: Effect of time and adsorbent dose on the removal of indigo dye

\section{Pseudo-first Order Adsorption Kinetics}

Several models can be used to express the mechanism of the adsorption onto an adsorbent. In order to investigate the mechanism of the adsorption, characteristic sorption constants were determined using Lagergren's pseudo-first order equation (based on solid capacity) and a pseudo- second order equation based on solid phase sorption respectively. A kinetic model for the pseudo-first order rate expression is in the form:

$\frac{d q(t)}{d t}=k_{1}\left(q_{e}-q(t)\right)$

Integrating this for the boundary conditions $q(0)=$ 0 and $q(t)=q_{t}$, and rearranging for linearized data plotting, Equation (3) becomes:

$$
\log \left(q_{e}-q_{t}\right)=\log q_{e}-\frac{k_{1}}{2.303} t
$$

4)

where:

$k_{1}=$ adsorption rate constant $\left(\mathrm{min}^{-1}\right)$,

$\mathrm{q}_{\mathrm{e}}=$ amount of solute adsorbed at equilibrium

$(\mathrm{mg} / \mathrm{g})$

$q_{t}=$ amount of solute adsorbed at any time $t$

$(\mathrm{mg} / \mathrm{g})$

The plot for pseudo-first order adsorption kinetics for indigo dye on CSB is shown in Figure 2.

\section{Pseudo-Second Order Adsorption Kinetics}

The pseudo-second order sorption kinetics is written in the form:

$\frac{d q(t)}{d t}=k_{2}\left(q_{e}-q(t)\right)^{2}$

Integrating this for the boundary conditions $q(0)=$ 0 and $q(t)=q_{t}$, and rearranging gives:

$\frac{t}{q_{t}}=\frac{1}{k_{2} q_{e}^{2}}+\left(\frac{1}{q_{e}}\right) t$

where:

$k_{2}=$ adsorption rate constant $\left(\mathrm{mg} \mathrm{g}^{-1} \mathrm{~min}^{-1}\right)$, and

$\mathrm{q}_{\mathrm{e}}=$ amount of solute adsorbed at equilibrium (mg/g) (Farhan et al., 2013)

The pseudo-second order kinetic model showed a better fit of experimental data as shown in Figure 3, with high coefficient of determination $\left(R^{2}\right)$ in the range of $0.9974-0.9994$ (Table 1). Also, the qe values obtained from the second order kinetics were found to be close to the experimental values. 


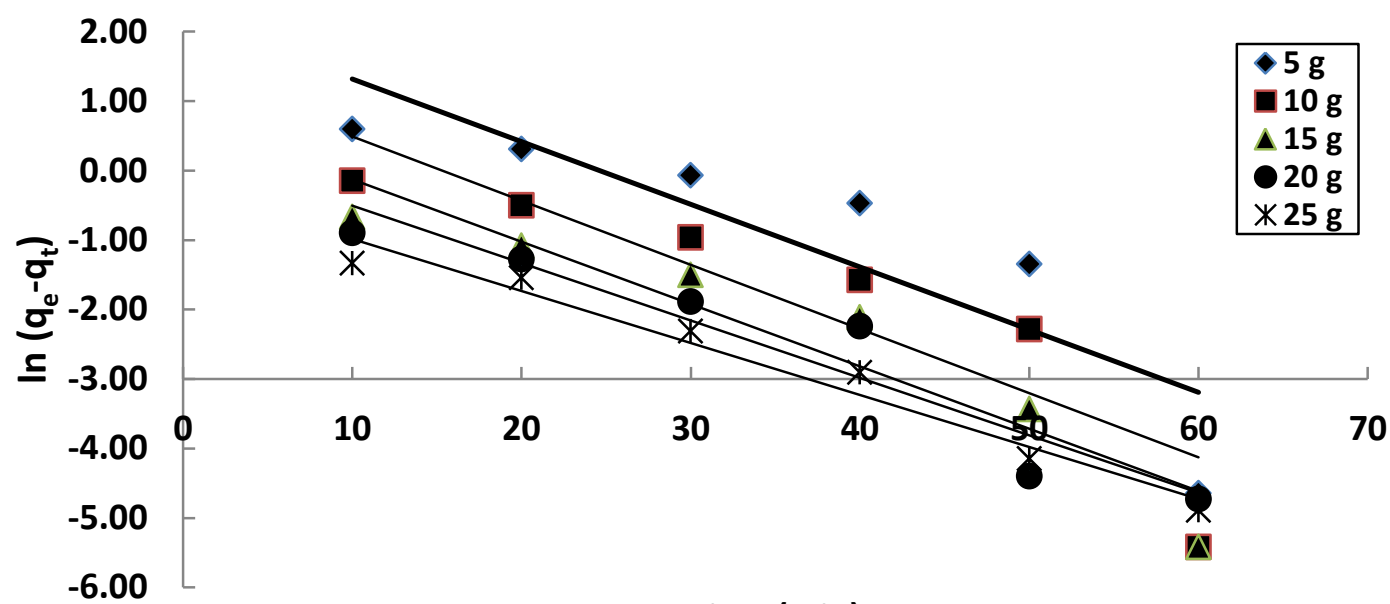

Time (min)

Figure 2: Pseudo-first order kinetics plot for indigo dye adsorption on CSB for the different adsorbent doses

The pseudo-first order adsorption kinetics (Figure 2) fairly fits the experimental data, with rather weak coefficient of determination $\left(R^{2}\right)$ in the range of $0.8161-0.9702$ as shown in Table 1. In many cases in literature, the Lagergen pseudofirst-order equation does not fit well for the whole range of contact time and is generally applicable over the initial period of the sorption process (Farhan et al., 2013; Awwad and Salem, 2014).

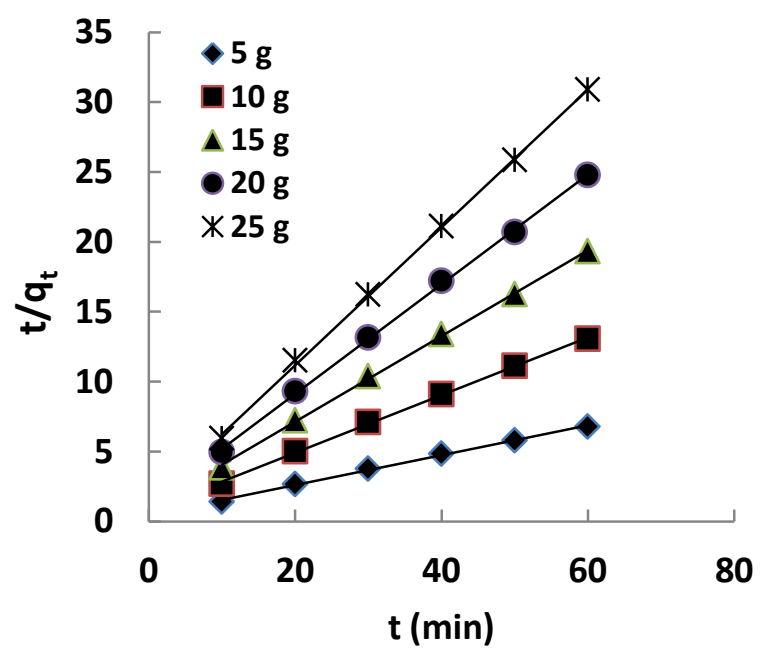

Figure 3: Pseudo-second order kinetics plot for indigo dye adsorption on CSB for the different adsorbent doses

Intra-particle diffusion kinetics

The intraparticle diffusion equation is given as:
$\mathrm{q}_{\mathrm{t}}=\mathrm{K}_{\mathrm{p}} \mathrm{t}^{0.5}+\mathrm{C} \quad(7)$

where $K_{p}(\mathrm{mg} / \mathrm{g} \mathrm{min} 0.5)$ is the intraparticle diffusion rate constant. A plot of $q_{t}$ against $t 0.5$ for each dose gave a straight line with slope $K_{p}$ and intercept $C$ as shown in Figure 4. The sorption mechanism assumes intra-particle diffusion only if the intercept $(\mathrm{C})$ is zero. However, this is not the case. The non-zero value of $C$ suggests the presence of an additional adsorption mechanism controlling the adsorption of indigo dye onto CSB other than intra-particle diffusion. This additional sorption mechanism may be due to boundary layer influence (that is, film resistance).

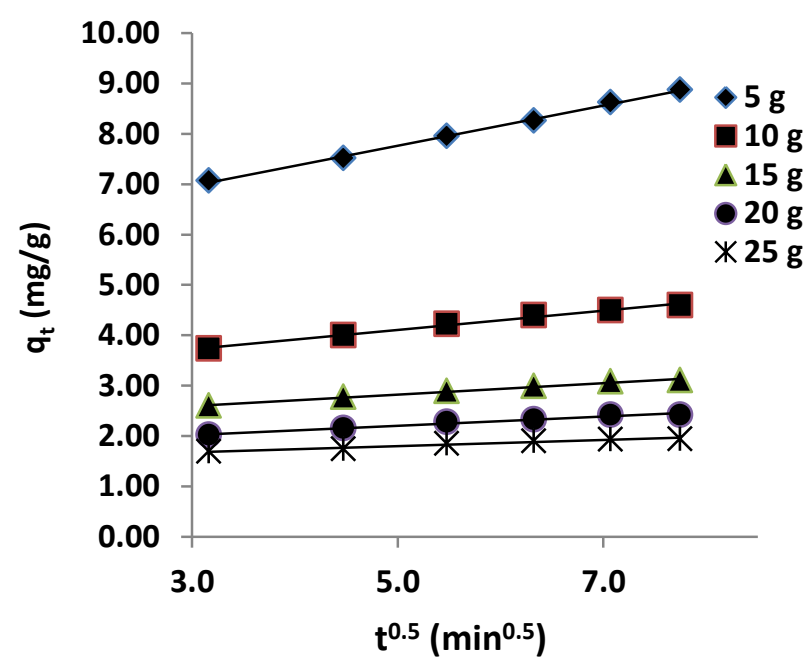

Figure 4: Intra-particle-diffusion model for adsorption of indigo dye on CSB 


\section{Equilibrium studies}

To quantify the adsorption capacity of adsorbents in relation to the dye, the experimental data points were fitted to linear form of the Langmuir and the Freundlich models in the concentration range investigated:

\section{Langmuir Isotherm}

Langmuir isotherm is an empirical isotherm based on four hypotheses (Zhang, 2007):

i. The surface of the adsorbent is uniform, that is, all the adsorption sites are equal.

ii. Adsorbed molecules do not interact.

iii. All adsorption occurs through the same mechanism.

iv. At the maximum adsorption, only a monolayer is formed: molecules of adsorbate do not deposit on other, already adsorbed, molecules of adsorbate, only on the free surface of the adsorbent.

For liquids (adsorbate) adsorbed on solids (adsorbent), the Langmuir isotherm can be expressed by

$$
q_{e}=\frac{q_{\max } k_{L} C_{e}}{1+k_{L} C_{e}}
$$

where:

$q_{e}=$ the equilibrium amount of adsorbate adsorbed per gram of the adsorbent.

$\boldsymbol{q}_{\max }=$ the maximum amount of adsorbate per gram of the adsorbent.

$k_{L}=$ the adsorption constant

$C_{e}=$ the equilibrium concentration of adsorbate in liquid

In a linearized form, the Langmuir isotherm is written in the form:

$\frac{1}{q_{e}}=\frac{1}{q_{\max } k_{L}}\left(\frac{1}{C_{e}}\right)+\frac{1}{q_{\max }}$

Table 1: Kinetic model parameters for different adsorbent doses

\begin{tabular}{|c|c|c|c|c|c|c|c|c|c|}
\hline \multirow[b]{2}{*}{$\begin{array}{c}\text { Dose } \\
\text { (g) }\end{array}$} & \multirow[b]{2}{*}{$\begin{array}{c}q_{e}(\exp ) \\
m g^{-1}\end{array}$} & \multicolumn{3}{|c|}{ Pseudo-first order } & \multicolumn{3}{|c|}{ Pseudo-second order } & \multicolumn{2}{|c|}{ Intra-particle model } \\
\hline & & $\begin{array}{c}k_{1} \\
\left(\min ^{-1}\right)\end{array}$ & $\begin{array}{c}\mathrm{qe}_{\mathrm{e}} \text { (cal) } \\
\left(\mathrm{mg} \mathrm{g} \mathbf{~}^{-}\right. \\
1)\end{array}$ & $\mathbf{R}^{2}$ & $\begin{array}{c}k_{2} \\
\left(\mathrm{~g} \mathrm{mg}^{-1} \mathrm{~min}^{-}\right. \\
\text {1) }\end{array}$ & $\begin{array}{c}q_{\mathrm{e}} \text { (cal) } \\
\left(\mathrm{mg} \mathrm{g}^{-1}\right)\end{array}$ & $\mathbf{R}^{2}$ & $\begin{array}{c}k_{i} \\
\left(\mathrm{mg} \mathrm{g}^{-1} \mathrm{~min}^{-}\right. \\
0.5)\end{array}$ & $\mathbf{R}^{2}$ \\
\hline (I) & & $\frac{0,1}{0,00}$ & 9.182 & $\overline{816}$ & 0.023 & & 007 & 0.398 & 0.9978 \\
\hline 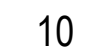 & & & 1.88 & & & & & & 9938 \\
\hline 15 & & 040 & .936 & 0.9913 & 0.095 & 3.2 & 3 & 0.1 & 0.9901 \\
\hline 20 & 2.4 & 088 & 1.516 & 0.9134 & 0.121 & 2.548 & 0.9992 & 0.091 & 0.9762 \\
\hline 25 & 90 & 0.065 & 0.668 & 0.9702 & 0.186 & 2.027 & 0.9994 & 0.061 & 0.9595 \\
\hline
\end{tabular}

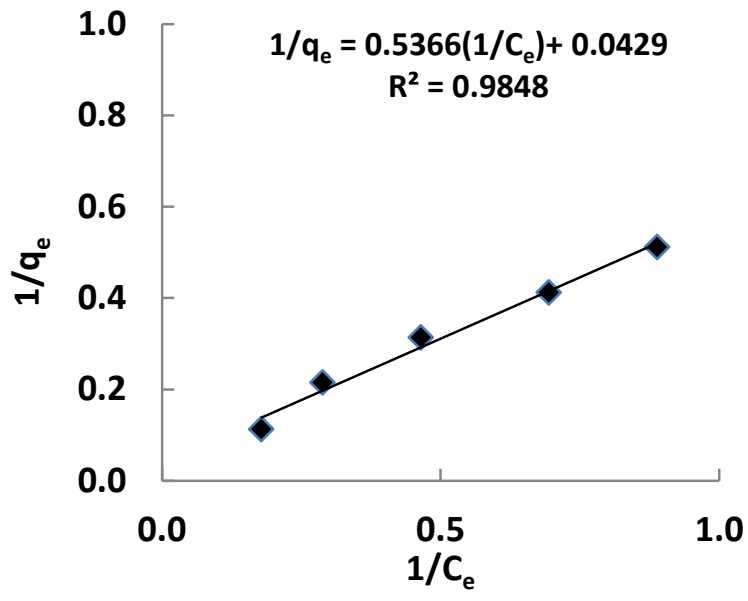

Figure 5: Langmuir isotherm for indigo dye adsorption on CSB
The essential characteristics of a Langmuir isotherm can be expressed in terms of a dimensionless equilibrium parameter, $\mathrm{R}_{\mathrm{L}}$ (Hall et al., 1966), which is defined by:

$R_{L}=\frac{1}{1+K_{L} C_{e}}$

The $R_{L}$ values indicate the type of the isotherm to be either unfavourable $\left(R_{L}>1\right)$, linear $\left(R_{L}=1\right)$, favourable $\left(0<R_{L}<1\right)$ or irreversible $\left(R_{L}=0\right)$. In the present work, the values obtained for $R_{L}$ ranged from 0.6906 (for $5 \mathrm{~g}$ adsorbent dose) to 0.9174 (for $25 \mathrm{~g}$ adsorbent dose), which clearly indicates that the adsorption was favourable. 


\section{Freundlich Isotherm}

This isotherm was pu blished by Freundlich and Küster in 1894 and is a purely empirical model based on a heterogeneous surface and is given by (Farhan et al, 2013):

$\mathrm{q}_{\mathrm{e}}=\mathrm{k}_{\mathrm{f}} \mathrm{C}_{\mathrm{e}}^{\frac{1}{\mathrm{n}}}$

where $\mathrm{k}_{\mathrm{f}}$ and $\mathrm{n}$ are empirical constants.

In a linearized form, this model becomes:

$\log q_{e}=\log k+\frac{1}{n} \log C_{e}$

Freundlich equilibrium constants were determined from the plot of $\log q_{e}$ against $\log C_{e}$, The value of $n$ indicates the degree of nonlinearity between solution concentration and adsorption as follows:

if $n=1$, then adsorption is linear;

if $n<1$, then adsorption is a chemical process;

if $n>1$, then adsorption is a physical process.

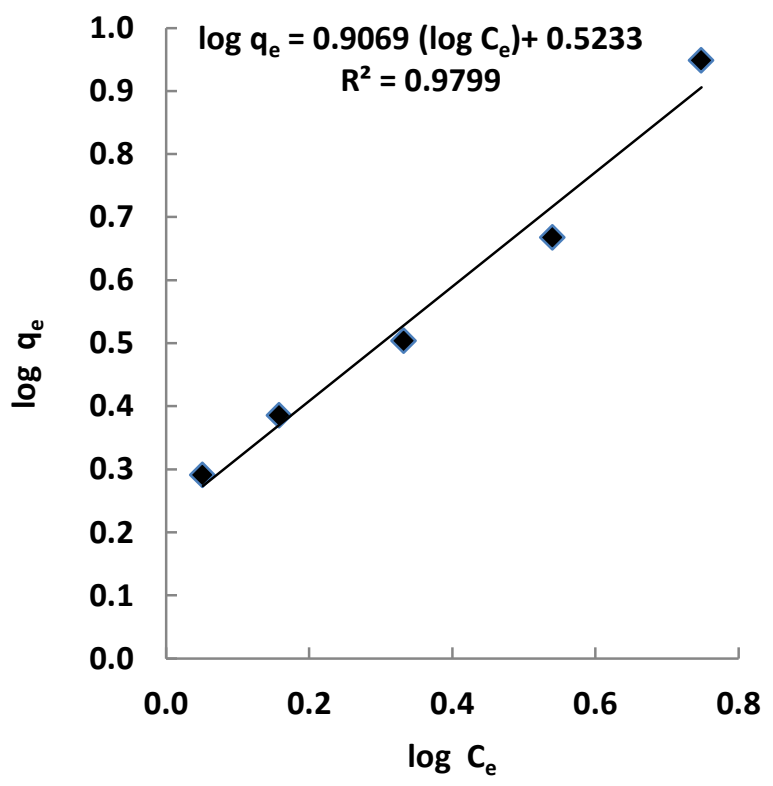

Figure 6: Freundlich isotherm for indigo dye adsorption on CSB

\begin{tabular}{cccccccccc}
\hline & & Langmuir & & \multicolumn{3}{c}{ Freundlich } & \multicolumn{3}{c}{ Temkin } \\
\hline Parameter & $\mathrm{K}_{\mathrm{L}}$ & $\mathrm{q}_{\max }$ & $\mathrm{R}^{2}$ & $\mathrm{k}_{\mathrm{f}}$ & $\mathrm{n}$ & $\mathrm{R}^{2}$ & $\mathrm{~B}$ & $\mathrm{~K}_{\mathrm{T}}$ & $\mathrm{R}^{2}$ \\
& 0.080 & 23.31 & 0.9848 & 1.688 & 1.10 & 0.9799 & 11508 & 0.6904 & 0.8847 \\
\hline
\end{tabular}

\section{CONCLUSION}

The study has shown that CSB is an effective sorbent for indigo dye. The Langmuir adsorption isotherm demonstrated the best correlation for
From Figure 6, the value of $\mathrm{n}$ was found to be 1.10 , which indicates that the adsorption of indigo dye onto CSB is a physical process.

The Temkin model takes into account the effects of the interaction of the adsorbate and the adsorbing species (Tempkin and Pyzhev, 1940). By ignoring the extremely low and large concentration values, the model assumes that the heat of adsorption of all of the molecules in the layer would decrease linearly rather than logarithmically with coverage due to adsorbateadsorbent interactions (Aharoni and Ungarish, 1977). The equation is stated as shown below (Aljeboree et al., 2014)

$q_{e}=\frac{R T}{b} \ln K_{T}+\frac{R T}{b} \ln C_{e}$

where $\mathrm{K}_{T}$ is the equilibrium binding constant ( $\mathrm{L}$ $\mathrm{mol}^{-1}$ ) corresponding to the maximum binding energy, $b$ is related to the adsorption heat, $R$ is the universal gas constant $\left(8.314 \mathrm{~J} \mathrm{~K}^{-1} \mathrm{~mol}^{-1}\right)$ and $\mathrm{T}$ is the temperature $(\mathrm{K})$.

The Langmuir, Freundlich and Temkin isotherm constants are presented in Table 2. From Table 2 , it can be seen that the regression correlation coefficient $\left(R^{2}\right)$ of the Langmuir equation $\left(R^{2}=\right.$ $0.9848)$ is more linear when compared with that of the Freundlich equation $\left(R^{2}=0.9799\right)$ and the Temkin equation $\left(R^{2}=0.8847\right)$, implying that the adsorption isotherm data are well fitted by the Langmuir isotherm. The monolayer adsorption capacity, according to the Langmuir isotherm, was found to be $23.31 \mathrm{mg} / \mathrm{g}$ at $30^{\circ} \mathrm{C}$.

Table 2: Isotherm parameters for the adsorption of indigo dye onto CSB the adsorption of indigo dye onto CSB, with the maximum monolayer adsorption capacity under experimental conditions was found to be 23.31 $\mathrm{g} / \mathrm{L}$. The pseudo second-order kinetic model 


\section{Nigerian Journal of Basic and Applied Science (June, 2017), 25(1): 40-47}

reflects better the dynamic behavior for the sorption of indigo dye onto CSB. The sorption process is principally particle diffusion controlled. It can be concluded that carbonised sugarcane bagasse may be used as a readily available lowcost adsorbent with high adsorption capacity for the removal of indigo dye from wastewater.

\section{REFERENCES}

Aharoni, C. and Ungarish, M. (1977) Kinetics of Activated Chemisorption. Part 2: Theoretical Models. Journal of the Chemical Society, Faraday Transactions, 73: 456-464.

Aljeboree, A. M., Alshirifi A. N. and Alkaim A. F. (2014) Kinetics and equilibrium study for the adsorption of textile dyes on coconut shell activated carbon. Arabian Journal of Chemistry, 10: S3381 - S3393.

Awwad, A. M. and Salem, N. M. (2014) Kinetics and thermodynamics of $\mathrm{Cd}(\mathrm{II})$ biosorption onto loquat (Eriobotrya japonica) leaves. Journal of Saudi Chemical Society, 18(5), 486-493

Bharathi, K. S. and Ramesh S. T. (2013) Removal of dyes using agricultural waste as low-cost adsorbents: a review. Applied Water Science, 3: 773-790.

Chieng, H. I., Lim, L. B. and Priyantha, N. (2015). Enhancing adsorption capacity of toxic malachite green dye through chemically modified breadnut peel: equilibrium, thermodynamics, kinetics and regeneration studies. Environmental technology, 36(1): 86-97

de Luna, M. D. G., Flores, E. D., Genuino, D. A. D., Futalan, C. M., and Wan, M. W. (2013) Adsorption of Eriochrome Black T (EBT) dye using activated carbon prepared from waste rice hullsOptimization, isotherm and kinetic studies. Journal of the Taiwan Institute of Chemical Engineers, 44(4): 646-653.

Farhan, A. M., Al-Dujaili, A. H. and Awwad A. M. (2013) Equilibrium and kinetic studies of cadmium(II) and lead(II) ions biosorption onto Ficus carcia leaves. International
:Journal of Industrial Chemistry, 424 31

Hall, K. R., Eagleton, L. C., Acrivos, A. and Vermeulen, T. (1966) Pore and Solid Diffusion Kinetics in Fixed Bed Adsorption under Constant Pattern Conditions. Industrial Engineering Chemistry Fundamantals , 5: 212-215.

Hameed, B. H., Mahmoud, D. K. and Ahmad A. L. (2008). Equilibrium modeling and kinetic studies on the adsorption of basic dye by a low cost adsorbent: Coconut (Cocosnucifera) bunch waste. Journal of Hazardous Materials, 158: 65-72

Mittal, A., Jhare D. and Mittal J. (2013) Adsorption of hazardous dye Eosin Yellow from aqueous solution onto waste material De-oiled Soya: Isotherm, kinetics and bulk removal. Journal of Molecular Liquids, 179:133-140.

Mohammed, R. R. and Chong, M. F. (2014) Treatment and decolorization of biologically treated Palm Oil Mill Effluent (POME) using banana peel as novel biosorbent. Journal of environmental management, 132: 237-249

Mohan, S.V, Prasad, K.K, Rao, N.C. and Sarma, P.N. (2005) Acid azo dye degradation by free and immobilized horseradish peroxidise (HRP) catalyzed process. Chemosphere, 58: 1097 - 1105

Qiu, M., Qian, C., Xu, J., Wu, J., and Wang, G. (2009) Studies on the adsorption of dyes into clinoptilolite. Desalination, 243: 286292.

Ragheb, S. M. (2013) Phosphate removal from aqueous solution using slag and fly ash. HBRC Journal, 9(3): 270-275.

Rizwana, P. S. and Uma, M. D. P. (2015) Decolourisation and Detoxification of Reactive Azo Dyes by Saccharothrix aerocolonigenes TE5. Journal of Applied \& Environmental Microbiology, 3(2): 58 62

Rodrigues, C. S., Madeira, L. M. and Boaventura R. A. (2013) Treatment of textile dye wastewaters using ferrous sulphate in a 
chemical coagulation/flocculation process. Environmental Technology, 34(5-8): $719-729$

Saroj, S., Singh, S. V. and Mohan, D. (2015) Removal of colour (Direct Blue 199) from carpet industry wastewater using different biosorbents (Maize Cob, Citrus Peel and Rice Husk). Arabian Journal for Science and Engineering, 40(6): 15531564

Sayal, A., Bulasara, V. K. and Barman S. (2012) A Study on Synthesis of Zeolite and Removal of Amido Black dye by adsorption with Zeolite. Chemical and Process Engineering Research, 2: 54 64

Sohrabi, M. R., Khavaran, A., Shariati, S., Shariati S. (2014) Removal of Carmoisine edible dye by Fenton and photo Fenton processes using Taguchi orthogonal array design. Arabian Journal of Chemistry. 10: S3523-S3531.

Su, Y., Zhao, B., Xiao, W. and Han, R. (2013) Adsorption behavior of light green anionic dye using cationic surfactant-modified wheat straw in batch and column mode. Environmental Science and Pollution Research, 20(8): 5558-5568.

Tempkin, M.l., and Pyzhev, V. 1940. Kinetics of ammonia synthesis on promoted iron catalyst. Acta Physicochimica URSS, 12: 327-356

Venceslau, M.C., Tom, S., Simon, J. J. (1994) Characterization of textile wastewaters: A review. Environmental Technology, 15: $917-929$.
Yavuz, Ö. and Aydin, A. H. (2006) Removal of Direct Dyes from Aqueous Solution Using Various Adsorbents. Polish Journal of Environmental Studies, 15(1): $155-161$

Zaharia, C., Suteu, D., Muresan, A., Muresan, R. and Popescu, A. (2009) Textile wastewater treatment by homogeneous oxidation with hydrogen peroxide. Environmental Engineering and Management Journal, 8(6): 1359-1369

Zaheer, S., Bhatti, H. N., Sadaf, S., Safa, Y. and Zia-ur-Rehman, M. (2014) Biosorption characteristics of sugarcane bagasse for the removal of foron blue E-BL dye from aqueous solutions. The Journal of Animal and Plant Sciences, 24(1): $272-279$

Zahrim, A.Y. and Hilal, N. (2013) Treatment of highly concentrated dye solution by coagulation/flocculation-sand filtration and nanofiltration. Water Resources and Industry, 3: 23-34

Zhang, K. (2007) UASB-aerobic Physicochemical treatment of dyeing wastewater. Resources and Environment, 13, 24 45.

Zheng, Y., Yu, S. , Shuai, S., Zhou Q., Cheng Q., Liu M. and Gao C. (2013) Color removal and $\mathrm{COD}$ reduction of biologically treated textile effluent through submerged filtration using hollow fiber nanofiltration membrane. Desalination, 314, 89-95 